\title{
Methane Catalytic Peroxide Oxidation Over Fe-Containing Zeolite
}

\author{
Vadim V. Boltenkov*a, Oxana P. Taran ${ }^{\mathrm{a}, \mathrm{b}}$, \\ Ekaterina V. Parkhomchuk ${ }^{\text {a,c }}$, Svetlana A. Yashnik ${ }^{a}$, \\ Kseniya A. Sashkina a , Artemiy B. Ayusheeva, \\ Dmitrii E. Babushkinn and Valentin N. Parmon ${ }^{\mathrm{a}, \mathrm{c}}$ \\ ${ }^{a}$ Boreskov Institute of Catalysis SB RAS \\ 5 Akad. Lavrentiev, Novosibirsk, 630090, Russia \\ ${ }^{b}$ Novosibirsk State Technical University \\ 20 Karl Marx, Novosibirsk, 630092, Russia \\ ${ }^{c}$ Novosibirsk State University \\ 2 Pirogova Str., Novosibirsk, 630090, Russia
}

Received 22.10.2016, received in revised form 14.11.2016, accepted 08.12.2016

The selectivity of Fe-MFI catalysts to partial peroxide oxidation of methane to methanol and formic acid was studied depending on their topology (Nanocrystals, Microcrystals, and bulk Commercial) and activation with oxalic acid. The catalysts were characterized by XRD, ICP-OES, SEM, UV-vis $D R, \mathrm{NH}_{3}-\mathrm{TPD}, \mathrm{N}_{2}$ adsorption. TOF of methane oxidation increased in the series: Nanocrystals < Microcrystals $<<$ Commercial. The selectivity to methanol depended mainly on the crystallite size and increased in the same series. The increase in TOF and selectivity to formic acid, as well as a sharp decrease in the selectivity to $\mathrm{CO}_{2}$ over all the activated catalysts were accounted for by an increase in the total acidity of the catalysts and the number of oligomeric Fe oxo-clusters. Different pathways to the formation of methanol/CO $\mathrm{C}_{2}$ (via free radical mechanism) and formic acid (via heterogeneous route) over Fe-MFI catalysts were suggested.

Keywords: methane, formic acid, methanol, Fe-ZSM-5, Fe-silicalite, peroxide oxidation.

DOI: 10.17516/1998-2836-2016-9-4-394-413.

(C) Siberian Federal University. All rights reserved

* Corresponding author E-mail address: vadim_boltenkov@catalysis.ru 


\section{Пероксидное каталитическое окисление метана}

на железосодержащих цеолитах

В.В. Болтенков ${ }^{\mathrm{a}}$, О.П. Таран ${ }^{\mathrm{a}, \tilde{0}}$, Е.В. Пархомчук ${ }^{\text {a, }}$, С.А. Яшника, К.А. Сашкина ${ }^{a}$, А.Б. Аюшеев ${ }^{\text {a }, ~ Д . Э . ~ Б а б у ш к и н ~}{ }^{\text {, }}$ В.Н. Пармон ${ }^{\text {a,в }}$ ${ }^{a}$ Институт катализа им. Г.К. Борескова СО РАН Россия, 630090, Новосибирск, пр. Академика Лаврентьева, 5 ${ }^{6}$ Новосибирский государственный технический университет Россия , 630092, Новосибирск, пр. Карла Маркса, 20

${ }^{8}$ Новосибирский государственный университет Россия, 630090, Новосибирск, ул. Пирогова, 2

Изучена селективность Fе-МFI-катализаторов в парциильном пероксидном окислении метана до метанола и муравьиной кислоть в зависимости от их топологии (нанокристалль, микрокристалль и массивный коммерческий) и активаџии щавелевой кислотой. Катализаторы изучень методами РФА, ИСП-ОЭС, СЭМ, ЭСДО, ТПД- $\mathrm{NH}_{3}$, адсорбции $\mathrm{N}_{2}$. ТОF окисления метана увеличивается в ряду: нанокристалль < микрокристалль << коммерческий. Селективность по метанолу зависит главным образом от размера кристаллитов и увеличивается в том же ряду. Увеличение ТОF и селективности по муравьиной кислоте, а также резкое снижение селективности по $\mathrm{CO}_{2}$ на всех активированных катализаторах были объяснены увеличением общей кислотности катализаторов и количества олигомерных оксокластеров железа. Высказано предположение о различных путях образования метанола/ $\mathrm{CO}_{2}$ (по свободнорадикальному марируту) и муравьиной кислотьл (по гетерогенному мармруту) на катализаторах Fe-MFI.

Ключевые слова: метан, муравьиная кислота, метанол, Fe-ZSM-5, Fe-силикалит, пероксидное окисление.

\section{Введение}

Огромные запасы метана на нашей планете и возможность его непрерывного восстановления в глобальном природном цикле углерода (около $10^{9}$ т в год) [1] делают метан очень привлекательным для решения многочисленных ресурсных и экологических проблем. Однако молекула метана химически очень инертна, энергия диссоциации связи С-Н в ней равна 440 кДж/ моль [2]. Таким образом, химическая активация метана является одной из проблем, имеющих глобальное значение для решения ресурсных и экологических проблем человечества [3].

Метанол, продукт реакции гидроксилирования метана, - востребованное сырье для химической промышленности [4]. Однако применяемый в настоящее время способ получения метанола через синтез-газ чрезвычайно энергоемкий процесс [5]. Следовательно, разработка прямого процесса низкотемпературного окисления метана в метанол продолжает оставаться 
актуальной проблемой в современном катализе $[6,7]$. Известные каталитические методы гидроксилирования метана в метанол с использованием $\mathrm{O}_{2}$ и $\mathrm{N}_{2} \mathrm{O}$ в качестве окислителей требуют высоких температур и давлений [8-15]. Таким образом, каталитическое пероксидное окисление метана в мягких условиях может стать альтернативой прямой каталитической функционализации метана (см. недавний обзор Olivos-Suarez и др. [16]) для решения различных проблем [17-20].

В то же время известно, что природные ферменты семейства метанмонооксигеназ, содержащие кластеры железа или меди, эффективно синтезируют метанол в мягких условиях, используя метан в качестве субстрата. С другой стороны, Fe- и Cu-содержащие цеолиты являются весьма активными и стабильными катализаторами жидкофазного пероксидного окисления разнообразных органических соединений [21-27], а также газофазного окисления метана [28, 29]. Fe- и $\mathrm{Cu}$-содержащие гидроксиды и цеолиты, как показано ранее, катализируют пероксидное окисление легких парафинов и олефинов [30,31], а также селективное окисление метана в метанол и/или муравьиную кислоту в мягких условиях (323 К) [29-31]. Однако мы не смогли найти какие-либо литературные данные, касающиеся влияния структурных и текстурных характеристик цеолитных катализаторов на селективность последнего процесса. Структура активного центра, ответственного за образование продуктов частичного окисления метана, в данный момент обсуждается. Например, в работах [32-34] сообщалось, что внекаркасные оксидные частицы железа содержат, скорее всего, биядерный активный центр $\mathrm{Fe}_{2} \mathrm{O}_{3}$, который катализирует глубокое окисление $\mathrm{CH}_{4}$. В этой же работе показано, что бренстедовские кислотные центры, хотя и удерживают субстрат на поверхности катализатора в отсутствие $\mathrm{Fe}$ содержащих, но не способны катализировать реакцию. С другой стороны, Шубин и др. рассматривают четырехъядерный активный центр $\mathrm{Fe}_{4} \mathrm{O}_{4}(\mathrm{OH})_{4}[35]$.

Данное исследование направлено на выявление влияния некоторых свойств цеолитов $\mathrm{Fe}-$ ZSM-5, таких как их морфология (размер кристаллитов и текстурные свойства) и структура $\mathrm{Fe}$-содержащих частиц в цеолитом каркасе, на селективность парциального пероксидного окисления метана в метанол и муравьиную кислоту. Катализаторы с различной морфологией (наноразмерные, микроразмерные и массивные) до и после активации щавелевой кислотой, обеспечивающей переход решетчатых ионов железа в тетраэдрическом окружении во внекаркасные частицы с октаэдрическим кислородным окружением [36], были испытаны в реакции и изучены физико-химическими методами.

\section{Материалы и методы}

Для приготовления катализаторов использовали тетрапропиламмония гидроксид (ТРАОН, 25\%-ный водный раствор, Acros), тетрапропиламмония бромид (TPABr, $98 \%$, Aldrich), тетраэтилортосиликат (TEOS, $\geq 98 \%$, Ангара-реактив), диоксид кремния (коллоидный, $\geq 99 \%$, Aldrich), этанол (95 \%, Фармация) и $\mathrm{Fe}\left(\mathrm{NO}_{3}\right)_{3} \cdot 9 \mathrm{H}_{2} \mathrm{O}$ ( $\geq 99 \%$, Merck). Для активации катализаторов применяли щавелевую кислоту $\left(\mathrm{H}_{2} \mathrm{C}_{2} \mathrm{O}_{4} \cdot 2 \mathrm{H}_{2} \mathrm{O}\right.$, Реахим). В реакциях разложения пероксида водорода и пероксидного окисления метана, а также для анализа реакционных растворов были использованы $\mathrm{H}_{2} \mathrm{O}_{2}$ (30 \%, База № 1 химреактивов), $\mathrm{CH}_{4}$ (99.9 \%, Московский газоперерабатывающий завод), $\mathrm{TiCl}_{4}$ (ОСЧ, Реахим) и $\mathrm{LiClO}_{4} \cdot 3 \mathrm{H}_{2} \mathrm{O}$ (ХЧ, Реахим). Вода Milli-Q (Millipore, France) была использована при приготовлении всех растворов.

$$
-396-
$$




\section{Синтез катализаторов}

Наноразмерный Fе-силикалит (образеи “Нанокристалль”) готовили по следующей методике: 120 мл TEOS, разбавленного 120 мл этанола, добавляли к 240 мл ТPAOH (12.5 \%) при интенсивном перемешивании в течение 20 мин, после чего по каплям добавляли раствор 2.6 г $\mathrm{Fe}\left(\mathrm{NO}_{3}\right)_{3} \cdot 9 \mathrm{H}_{2} \mathrm{O}$ в 5 мл дистиллированной воды. После перемешивания в течение 20 мин прозрачный светло-желтый гель с молярным составом $1.00 \mathrm{SiO}_{2}: 0.28 \mathrm{TPAOH}: 0.006 \mathrm{Fe}_{2} \mathrm{O}_{3}: 4.79 \mathrm{EtOH}$ : $1.75 \mathrm{H}_{2} \mathrm{O}$ загружали в покрытый тефлоном автоклав из нержавеющей стали и подвергали гидротермической обработке при $363 \mathrm{~K}$ в течение 7 дней. Полученную молочную суспензию $\mathrm{Fe}-$ силикалита очищали в три этапа, которые включали в себя: центрифугирование в течение 5 ч при относительном ускорении $3000 \mathrm{~g}$ с последующим удалением маточного раствора и повторным диспергированием в дистиллированной воде с одновременной ультразвуковой обработкой. Очищенный Fe-силикалит отделяли центрифугированием и сушили при $323 \mathrm{~K}$ в течение 12 ч.

Микроразмерный Fe-силикалит (образеи “Микрокристалль”) синтезировали с использованием раствора предшественника со следующим составом: $1.00 \mathrm{SiO}_{2}: 0.1 \mathrm{Na}_{2} \mathrm{O}: 0.11 \mathrm{TPABr}$ : $0.006 \mathrm{Fe}_{2} \mathrm{O}_{3}: 25 \mathrm{H}_{2} \mathrm{O}$. Процедура синтеза была следующей: 40 г диоксида кремния постепенно добавляли к водному раствору, содержащему 5.36 г $\mathrm{NaOH}$ и 19.5 г ТРАBr при постоянном перемешивании на магнитной мешалке при комнатной температуре. После перемешивания в течение 15 мин по каплям добавляли 3.2 г $\mathrm{Fe}\left(\mathrm{NO}_{3}\right)_{3} \cdot 9 \mathrm{H}_{2} \mathrm{O}$, растворенные в 5 мл дистиллированной воды, для получения суспензии. После дополнительного перемешивания в течение 10 мин суспензию переносили в автоклав из нержавеющей стали, покрытый тефлоном. Автоклав выдерживали в печи при $433 \mathrm{~K}$ в течение 72 ч. После гидротермальной обработки твердый продукт отфильтровывали, промывали дистиллированной водой и сушили при $373 \mathrm{~K}$ в течение 12 ч.

Коммерческий образец H-ZSM-5 с соотношением Si/Al (цеолитный модуль), равным 30 (образец “Коммерческий”), был произведен на Новосибирском заводе химических концентратов (Новосибирск, Россия). Данный цеолит был исследован набором физико-химических методов ранее [37] и является хорошо кристаллизованным цеолитом со степенью кристалличности не менее $95 \%$. Данные ${ }^{27} \mathrm{Al}$ ЯМР показали отсутствие в образце внерешетчатых ионов $\mathrm{Al}^{3+}$. Начальное содержание $\mathrm{Fe}$ в образце - 0.65 вес. \%; катионы $\mathrm{Fe}^{3+}$ стабилизировались преимущественно в виде отдельных ионов в тетраэдрических позициях решетки цеолита ( $\left.\mathrm{Fe}^{3+} \mathrm{Td}\right)$ [37].

Все катализаторы были прокалены при 773 K в течение 5 ч. Часть прокаленных образцов активировали с помощью щавелевой кислоты следующим образом. Порошки прокаленных катализаторов добавляли к 1 М водному раствору щавелевой кислоты до концентрации 100 г/л и перемешивали в течение 30 мин при $323 \mathrm{~K}$. Затем образцы фильтровали и промывали дистиллированной водой до $\mathrm{pH}=7.0$, сушили на воздухе при $323 \mathrm{~K}$ в течение 12 ч и прокаливали при $773 \mathrm{~K}$ в течение 3 ч. Затем порошки Fе-силикалитов измельчали в керамической ступке и фракцию < 200 мкм отделяли просеиванием. Синтезированные образцы обозначены: «Нанокристаллы актив.», «Микрокристалль актив.», «Коммерческий актив.» соответственно (табл. 1).

\section{Физико-химические методы исследования катализаторов}

Рентгенофазовый анализ (РФА) порошков катализаторов проводили с использованием дифрактометра Siemens D500 (Siemens, Южная Корея) с излучением Сu K $\alpha$ ( $\lambda=0.154 \mathrm{~nm})$.

$$
-397-
$$


Таблица 1. Физико-химические характеристики Fe-содержащих катализаторов

\begin{tabular}{|c|l|c|c|c|c|c|}
\hline Номер & \multicolumn{1}{|c|}{ Катализатор } & $\begin{array}{c}\text { Содержание } \\
\mathrm{Fe}, \%\end{array}$ & $\mathrm{~S}_{\text {Бэт, } \mathrm{M}^{2} / \Gamma}$ & $\mathrm{S}_{\text {внеш., } \mathrm{M}^{2} / \Gamma}$ & $\mathrm{V}_{\text {общ. }} \mathrm{cm}^{3 / \Gamma}$ & $\mathrm{V}_{\text {микро., }} \mathrm{cm}^{3 / \Gamma}$ \\
\hline 1 & Нанокристаллы & 1.32 & 524 & 234 & 0.68 & 0.12 \\
\hline 2 & Нанокристаллы актив. & 1.20 & 480 & 205 & 0.69 & 0.11 \\
\hline 3 & Микрокристаллы & 1.42 & 398 & 107 & 0.19 & 0.12 \\
\hline 4 & Микрокристаллы актив. & 1.42 & 437 & 117 & 0.22 & 0.13 \\
\hline 5 & Коммерческий & 0.65 & 517 & 19 & 0.28 & 0.13 \\
\hline 6 & Коммерческий актив. & 0.65 & 426 & 12 & 0.23 & 0.17 \\
\hline
\end{tabular}

Гидродинамические диаметры частиц цеолита в суспензии измеряли методом лазерной дифракции на приборе Zetasizer Nano (Malvern, Великобритания).

Химический состав образцов исследовали методом оптической эмиссионной спектрометрии с индуктивно связанной плазмой на приборе Optima 4300 DV (PerkinElmer Inc., США).

Изображения сканирующей электронной микроскопии (СЭМ) получены на микроскопе JSM-6460LV (JEOL, Япония) при рабочем напряжении 15-20 кB.

Изотермы адсорбции-десорбции азота измеряли с помощью анализатора площади поверхности Autosorb-6B-Kr (Quantachrome, США) при 77 K. Перед анализом образцы дегазировали при $573 \mathrm{~K}$ в течение 10 ч. Удельную площадь поверхности вычисляли по уравнению БЭТ [38]. Объем микропор и площадь внешней поверхности рассчитывали с помощью $\alpha$-метода, используя изотермы адсорбции азота $\mathrm{N}_{2}$ на силикагеле LiChrospher Si-1000 в качестве стандарта $[39,40]$.

Спектры ЭСДО регистрировали с помощью спектрофотометра UV-2501 PC (Shimadzu, Япония) в диапазоне волновых чисел 11 000-54 $000 \mathrm{~cm}^{-1}$ при $298 \mathrm{~K}$.

Кислотные свойства образцов определяли методом термопрограммируемой десорбции аммиака (ТПД- $\mathrm{NH}_{3}$ ) на калиброванном лабораторном стенде. Количество аммиака определяли с помощью квадрупольного масс-спектрометра HiCube RGA100. Температурный контроль осуществляли температурным контроллером Termodat 13KT2/5T, обеспечивающим равномерную скорость нагрева образца.

\section{Испытания катализаторов}

Каталитическое окисление метана проводили в автоклаве объемом 450 мл из материала хастеллой (AMAR, India) при интенсивном перемешивании (1500 об/мин) мешалкой типа пропеллера с магнитным приводом. В типичном эксперименте 1 M раствор $\mathrm{H}_{2} \mathrm{O}_{2}$ (80 мл) помещали в реактор. Реактор герметизировали, 5 раз продували метаном при комнатной температуре и начинали нагрев. Автоклав нагревали до необходимой температуры реакции 323 К. После достижения температуры реакции в реактор подавали катализатор (216 мг) с помощью шарового клапана системы загрузки катализаторов. В системе фиксировали рабочее давление метана (30 бар), раствор энергично перемешивали при 1500 об/мин и выдерживали при температуре реакции в течение 30 мин. После окончания реакции газовую фазу отбирали с помощью системы газового пробоотбора и анализировали методом ГХ. Реакционный раствор фильтровали

$$
-398-
$$


на ацетат-целлюлозном фильтре с порами размером 0.45 мкм и анализировали методами ГХ, ВЭЖХ.

Холостой эксперимент проводили в аналогичных условиях, но в отсутствие катализатоpa.

При исследовании каталитической активности смытого в раствор Fe после реакции использовали раствор, полученный после реакции окисления метана на коммерческом актив. катализаторе. Дополнительное количество перекиси водорода добавляли к раствору, чтобы достичь начальной концентрации в $1 \mathrm{M} \mathrm{H}_{2} \mathrm{O}_{2}$. Реакцию проводили обычным способом.

В реакции с раствором $\mathrm{Fe}\left(\mathrm{NO}_{3}\right)_{3}$ концентрация соли $(0.31 \mathrm{MM})$ была выбрана эквивалентной концентрации $\mathrm{Fe}$, вводимому в раствор вместе с коммерческим катализатором.

Формальные активности (TOF) катализаторов в реакциях окисления метана (в пересчете на содержание железа в образцах) и разложения пероксида водорода рассчитывались с использованием общего количества продуктов окисления метана и общего количество прореагировавшего пероксида водорода по формулам

$$
\begin{aligned}
& \operatorname{TOF}\left(\mathrm{CH}_{4}\right)=\frac{v\left(\mathrm{CO}_{2}\right)+v(\mathrm{CO})+v\left(\mathrm{CH}_{3} \mathrm{OH}\right)+v(\mathrm{CHOOH})}{v(\mathrm{Fe}) \cdot t(\text { реакиии })}, \\
& \operatorname{TOF}\left(\mathrm{H}_{2} \mathrm{O}_{2}\right)=\frac{v\left(\mathrm{H}_{2} \mathrm{O}_{2}\right)}{v(\mathrm{Fe}) \cdot t(\text { реакции })},
\end{aligned}
$$

где $v(\mathrm{CO}), v\left(\mathrm{CO}_{2}\right), v\left(\mathrm{CH}_{3} \mathrm{OH}\right), v(\mathrm{CHOOH})$ - количества моль $\mathrm{CO}, \mathrm{CO}_{2}, \mathrm{CH}_{3} \mathrm{OH}$, и $\mathrm{CHOOH}$, образовавшихся в процессе реакции соответственно; $v\left(\mathrm{H}_{2} \mathrm{O}_{2}\right)$ - количество моль прореагировавшего пероксида водорода; $v(\mathrm{Fe})$ - количество моль активного металла (Fe) в катализаторе; $\mathrm{t}$ (реакции) - время реакции равное, 0.5 ч. Вычисленное таким образом значение ТОF является его нижним пределом, так как его реальное значение должно рассчитываться на концентрацию каталитически активных центров катализатора, однако их точное количество может быть определено только после установления механизма реакции.

Селективность индивидуальных продуктов, образовавшихся в ходе реакции, рассчитывали по следующей формуле:

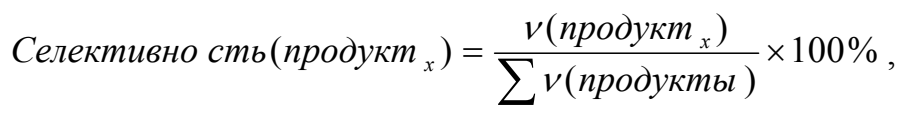

где $v($ продукт $)$ - количество моль $\mathrm{CO}, \mathrm{CO}_{2}, \mathrm{CH}_{3} \mathrm{OH}$ или $\mathrm{CHOOH,} \mathrm{образовавшегося} \mathrm{в} \mathrm{ходе} \mathrm{реак-}$

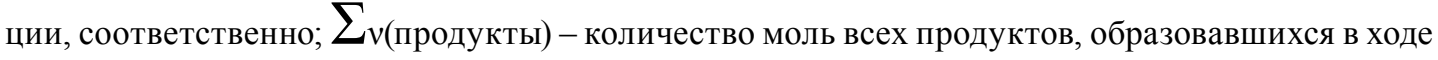
реакции.

Разложение $\mathrm{H}_{2} \mathrm{O}_{2}$. Цеолитные катализаторы были испытаны в реакции разложения $\mathrm{H}_{2} \mathrm{O}_{2}$ в 5 мл термостатируемом стеклянном статическом реакторе при перемешивании с помощью магнитной мешалки. Кинетические кривые выделения $\mathrm{O}_{2}$ записывали по изменению давления в системе с помощью датчика давления. Условия реакции: объем (V) 2.5 мл, концентрация катализатора 20 г/л, 298-323 K, начальная концентрация $\mathrm{H}_{2} \mathrm{O}_{2} 1$ М. Реакцию проводили до полного разложения пероксида водорода. Константу скорости реакции первого порядка определяли по прямолинейной анаморфозе в координатах первого порядка. Кажущуюся энергию активации

$$
-399 \text { - }
$$


( $\left.\mathrm{E}_{\mathrm{a}}\right)$ рассчитывали в аррениусовских координатах. TOF катализаторов в разложении пероксида водорода рассчитывали по следующей формуле:

$$
\operatorname{TOF}\left(\mathrm{H}_{2} \mathrm{O}_{2}\right)=\frac{\mathrm{C}_{0}\left(\mathrm{H}_{2} \mathrm{O}_{2}\right) \cdot k \cdot V}{v(\mathrm{Fe})} .
$$

\section{Аналитические методики}

Состав газовой фазы определяли на газовом хроматографе «Кристалл 2000М» («Хроматек», Россия), оснащенном пламенно-ионизационном детектором, метанаторном и колонкой 2 м × 2 мм, заполненной сорбентом Хромосорб 102. Аргон выступал в качестве газа носителя.

Состав жидкой фазы анализировали двумя способами. Содержание метанола определяли методом газовой хроматографии на хроматографе «Кристалл 2000М», оснащенном пламенноионизационным детектором и капиллярной колонкой EQUITY ${ }^{\mathrm{TM}}-5$ (Supelco, CША), 30 м × 0.32 мм $\times 0.25$ мкм (толщина пленки). В качестве газа-носителя использовали аргон. Концентрацию муравьиной кислоты определяли методом ВЭЖХ на жидкостном хроматографе «Миллихром А02» (Институт хроматографии «ЭкоНова», Россия), оснащенном спектрометрическим детектором ( $\lambda=210$ нм) и ионообменной колонкой «Диасфер-250ПА», 2 мм $\times 75$ мм. Элюенты: $0.04 \mathrm{M}$ водный раствор $\mathrm{LiClO}_{4}$ и $\mathrm{H}_{2} \mathrm{O}$; скорость потока 0.2 мл/мин.

\section{Результаты и обсуждение}

\section{Исследование катализаторов}

набором физико-химических методов

Содержание Fе в исходных катализаторах варьировалось от $1.42 \%$ (Fе-силикалиты) до $0.65 \%$ (коммерческий H-ZSM-5). Активация катализаторов щавелевой кислотой не привела к значительному вымыванию активного компонента. Максимальная потеря Fе наблюдалась только для нанокристаллов (9.1\%).

Текстурные свойства как нанокристаллов и микрокристаллов, так и коммерческого катализатора обсуждались в работах, опубликованных ранее ([41] и [37] соответственно). Для исходных катализаторов характерны высокие значения общей площади поверхности по БЭТ $\left(\mathrm{S}_{\text {Бэт }}\right)(398-524$ м²/г) (табл. 1), для нанокристаллов и микрокристаллов - высокие значения площади внешней поверхности $\left(\mathrm{S}_{\text {внеш. }}\right)$.

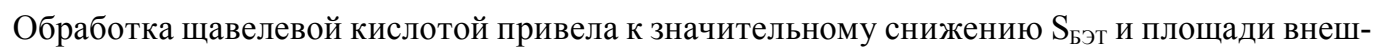
ней поверхности для нанокристаллов и коммерческого катализаторов. Небольшое снижение объема микропор с одновременным расширением мезопор для нанокристаллов, вероятно, связано с частичным растворением оксида кремния и/или железа. Напротив, для микрокристал-

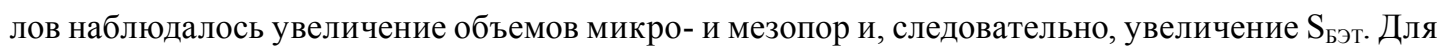
коммерческого цеолита характерно снижение объема как микро-, так и мезопор, что привело к снижению $\mathrm{S}_{\text {Бэт }}$ и $\mathrm{S}_{\text {внеш. }}$ за счет удаления внекаркасных комплексов алюминия с внешней поверхности кристаллов цеолита или извлечения ионов железа из каркаса на внекаркасные позиции. Различный эффект активации на текстурные и каталитические характеристики можно объяснить различным состоянием железа в нанокристаллах, микрокристаллах и коммерческом катализаторе. 
Исследования методом СЭМ показали средний размер 180 нм для нанокристаллов, однако для микрокристаллов наблюдается широкое распределение по размерам (от 2 до 10 мкм). Коммерческий катализатор представляет собой более крупные частицы (более 10 мкм), состоящие из агрегатированых кристаллов различных форм и размеров.

Рентгенограммы для всех Fе-силикалитов и коммерческого катализатора являются типичными для цеолитов со структурой MFI с высокой степенью кристалличности (рис. 1). Активация образцов щавелевой кислотой с последующим прокаливанием приводит к небольшому снижению кристалличности из-за образования дефектов, вызванных миграцией катионов металлов $\left(\mathrm{Fe}^{3+}\right.$ и $\left.\mathrm{Al}^{3+}\right)$ из каркасных позиций, и частичному растворению их структуры. Уменьшение интенсивности линий при $22-25{ }^{\circ} \mathrm{C}$ может свидетельствовать о заполнении каналов цеолита внекаркасными комплексами железа и/или алюминия, которые могут быть причиной уменьшения объема микропор в активированном коммерческом катализаторе.

Состояние частиц железа в катализаторах изучено методом ЭСДО (рис. 2). Сильное поглощение на 30 000-50 $000 \mathrm{~cm}^{-1}$ наблюдалось для всех образцов. Полосы поглощения на 41000 и $46000 \mathrm{~cm}^{-1}$ относятся к переносу заряда $\mathrm{O}^{2-}$ лиганд $\rightarrow$ металл с участием $\mathrm{Fe}^{3+}$ в октаэдрическом $\left(\mathrm{Fe}^{3+}{ }_{\mathrm{oh}}\right)$ и тетраэдрическом $\left(\mathrm{Fe}^{3+}{ }_{\mathrm{Td}}\right)$ окружениях кислорода. Поглощение на $31000-33000 \mathrm{~cm}^{-1}$ в ЭСДО-спектрах в исходных и активированных образцах указывает на наличие $\mathrm{Fe}_{2} \mathrm{O}_{3}$-подобных агрегатов с ионами $\mathrm{Fe}^{3+}$ оh в кислородсодержащем окружении, но вклад этой фракции невозможно измерить с помощью данного метода. Наблюдается существенное различие между ЭСДОспектрами на 31 000-33000 см-1 для исходных и активированных микрокристаллов (рис. 2). Таким образом, активация микрокристаллов вызывает значительную миграцию частиц железа с последующим их агрегатированием в железокислородные частицы.

Увеличение интенсивности линий поглощения на $41000-46000 \mathrm{~cm}^{-1}$ свидетельствует о формировании изолированных ионов $\mathrm{Fe}^{3+}$ в октаэдрическом окружении кислорода после активации щавелевой кислотой для нанокристаллов и коммерческого катализатора. Исходные и активированные нанокристаллы и коммерческий катализаторы также содержат железокис-

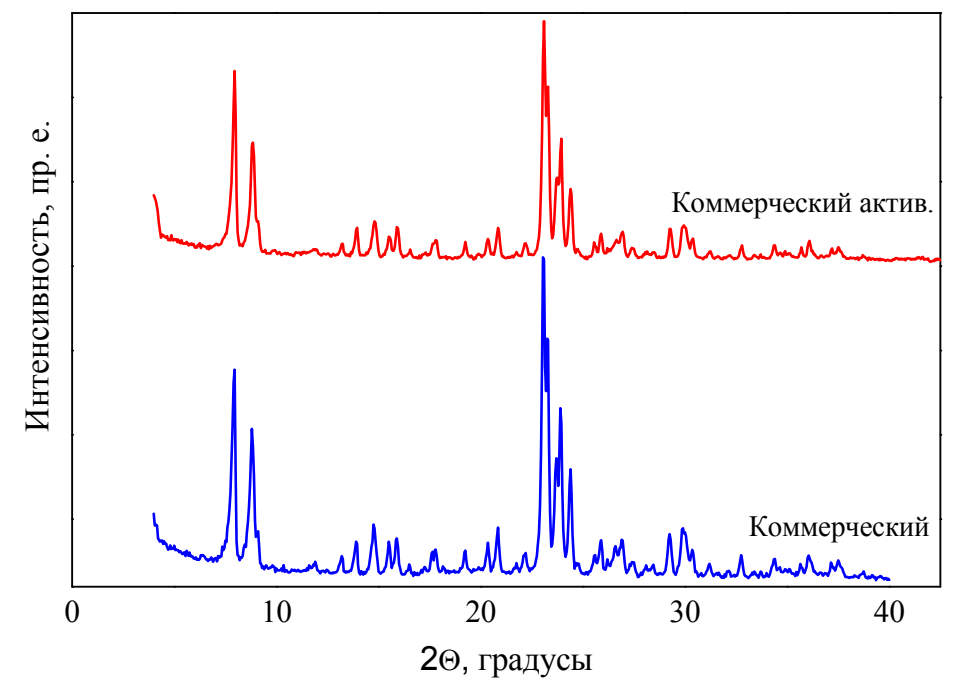

Рис. 1. РФА-спектры для исходного и активированного коммерческого Fe-ZSM-5

$$
-401-
$$




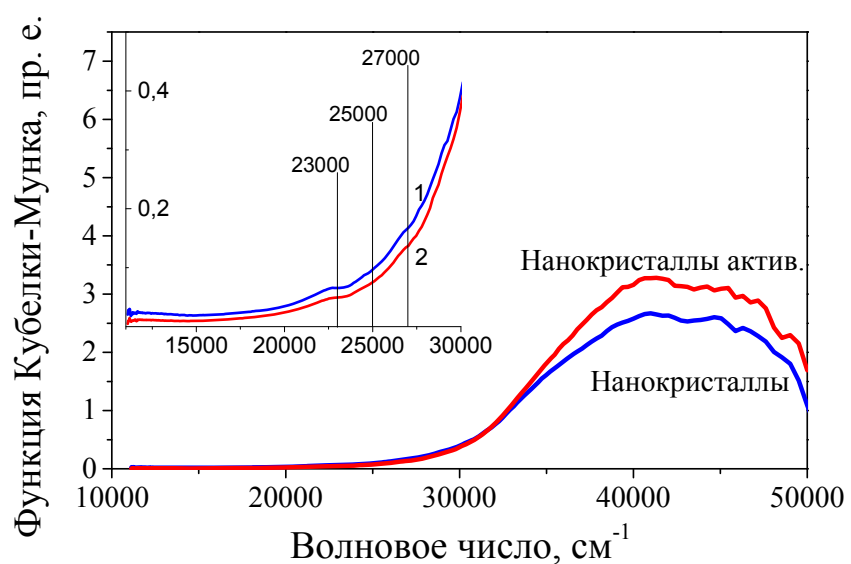

Б

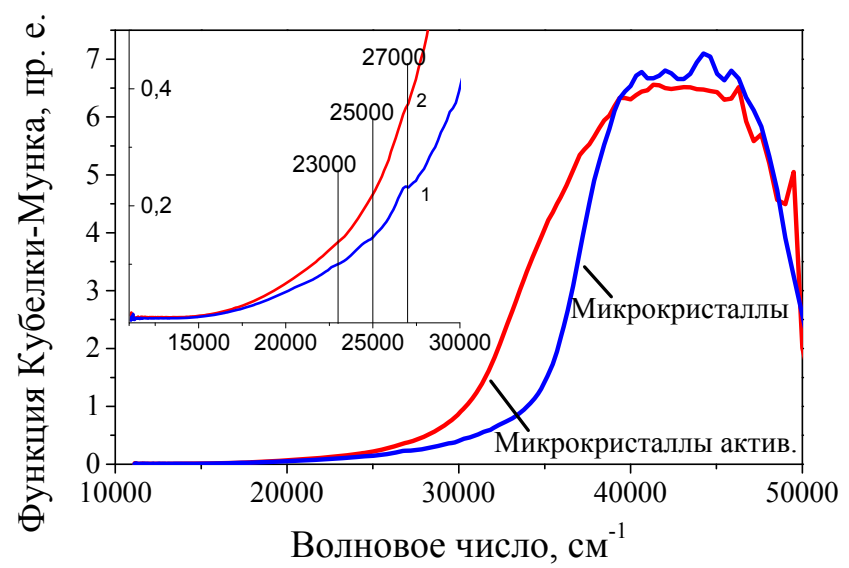

$\mathrm{B}$

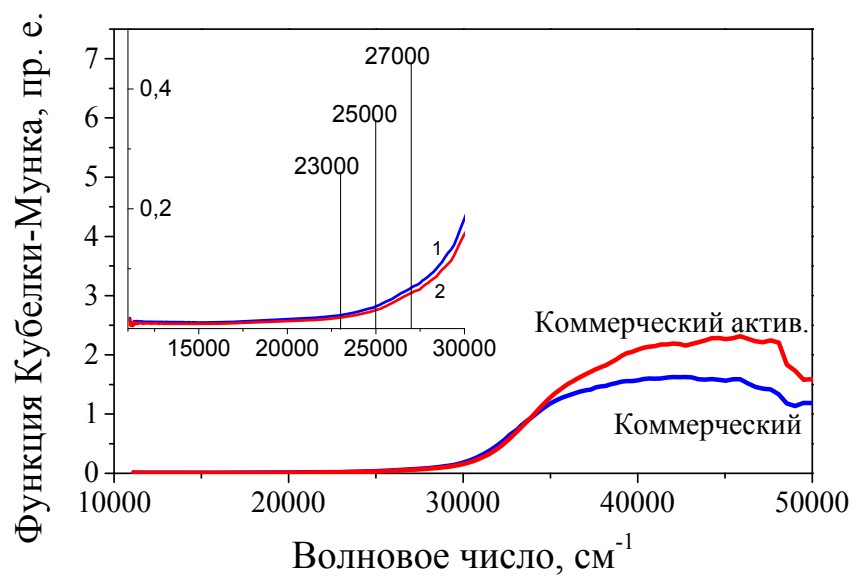

Рис. 2. ЭСДО-спектры для исходных (1) и активированных (2) нанокристаллов (А), микрокристаллов (Б) и коммерческого (В) катализаторов 
лородные олигомерные комплексы или кластеры $\mathrm{Fe}^{3+}$ oh, для которых характерен d-d-переход на $12000 \mathrm{~cm}^{-1}$ и ППЗ $\mathrm{O}^{2-}-\mathrm{Fe}^{3+}$ на 20000 и 25 000-28 $000 \mathrm{~cm}^{-1}$ [42]. Однако трудно оценить изменения концентраций олигомерных комплексов или кластеров в процессе активации из-за низкой экстинкции указанных полос поглощения. Менее интенсивные полосы на 23 000, 25000 и $27000 \mathrm{~cm}^{-1}$, относящихся к d-d-переходам ионов $\mathrm{Fe}^{3+}{ }_{\mathrm{Td}}$ в тетраэдрической координации, указывают на то, что каркасное железо преобразуется в олигомерные и изолированные комплексы $\mathrm{Fe}^{3+}$ [43]. Не исключено, что олигомерные и изолированные комплексы $\mathrm{Fe}^{3+}$ являются результатом разрушения $\alpha-\mathrm{Fe}_{2} \mathrm{O}_{3}$-подобных кластеров за счет образования хелатных комплексов с катионами $\mathrm{Fe}^{3+}$ в процессе обработки щавелевой кислотой.

Метод термопрограмируемой десорбции (ТПД- $\mathrm{NH}_{3}$ ) аммиака использовали для определения кислотных свойств катализаторов (рис. 3). Низкотемпературный пик (1-пик) при температуре около $430 \mathrm{~K}$ наблюдается в спектрах ТПД- $\mathrm{NH}_{3}$ аммиака всех исследованных образцов, как и плечо при $520 \mathrm{~K}$, которое более выражено для коммерческого катализатора. L-пик соответствует аммиаку, адсорбированному на терминальных ОН-группах [44] и Льюисовских кислотных центрах [45]. Кроме того, высокотемпературные пики (h-пики), которые, как правило, ассоциируются с сильными кислотными центрами бренстедовской природы [46, 47], наблюдаются в спектрах нанокристаллов и коммерческого катализатора. В случае нанокристаллов при активации наблюдается смещение высокотемпературных пиков (h-пики) с 700 до $645 \mathrm{~K}$, что указывает на ослабление силы кислотных центров, по-видимому, из-за частичного выщелачивания железа. В профиле микрокристаллов отсутствует h-пик, однако присутствует длинное плечо, которое предполагает наложение пиков, относящихся к кислотным центрам различной природы. Высокотемпературный пик при $647 \mathrm{~K}$, наблюдающийся в профиле ТПД- $\mathrm{NH}_{3}$ образца микрокристаллов активированных, вызван развитием структуры мезопор и улучшением доступности для аммиака бренстедовских кислотных центров в каналах цеолита. ТПД- $\mathrm{NH}_{3}$ профиль коммерческого цеолита существенно отличается благодаря наличию алюминия в образце: на ТПД- $\mathrm{NH}_{3}$-профиле присутствует пик при $520 \mathrm{~K}$ на месте 1-пика, a h-пик, наблюдаемый при высокой температуре $720 \mathrm{~K}$ (рис. 3). После активации коммерческого образца увеличивается 1-пик при $520 \mathrm{~K}$, а интенсивность 1-пика при $430 \mathrm{~K}$ уменьшается из-за изменения концентрации терминальных ОН-групп и формирования льюисовских кислотных центров. Кроме того, h-пик не смещается к более низкой температуре, следовательно, после активации сила бренстедовских кислотных центров не меняется. Суммарная адсорбция $\mathrm{NH}_{3}$-цеолитами рассчитывалась путем интегрирования площади под профилями ТПД (рис. 4). В итоге можно сказать, что коммерческий образец является более кислым, чем Fе-силикалиты, количество кислотных центров в которых почти в два раза меньше, чем в первом.

\section{Разложение $\mathrm{H}_{2} \mathrm{O}_{2}$}

В процессе пероксидного окисления метана протекают, по крайней мере, две конкурирующие реакции, а именно: целевое пероксидное окисление субстрата и побочное - каталитическое разложение перекиси водорода. В связи с этим важно понять, как процедура подготовки катализаторов влияет на каталитическую активность в разложении пероксида водорода и как активация катализатора влияет на кинетику данного процесса.

$$
-403-
$$


A

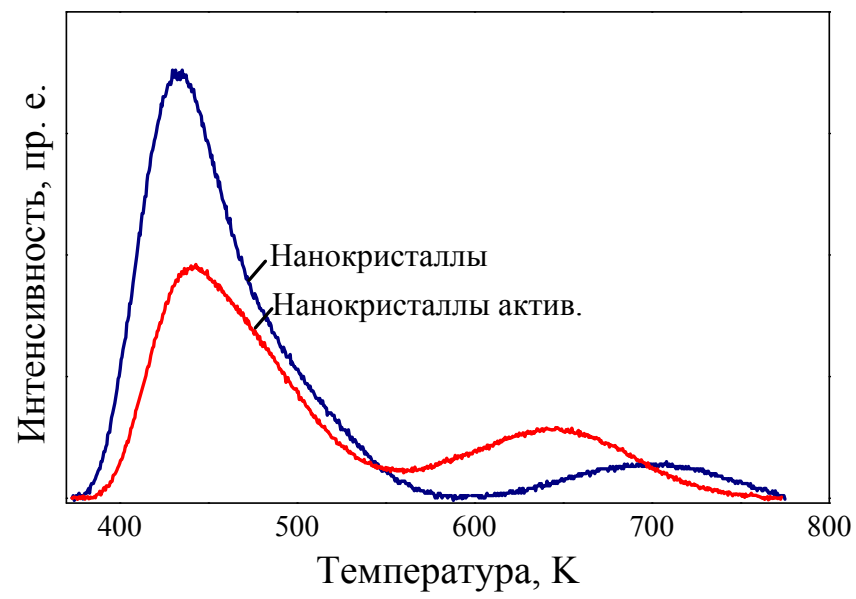

Б

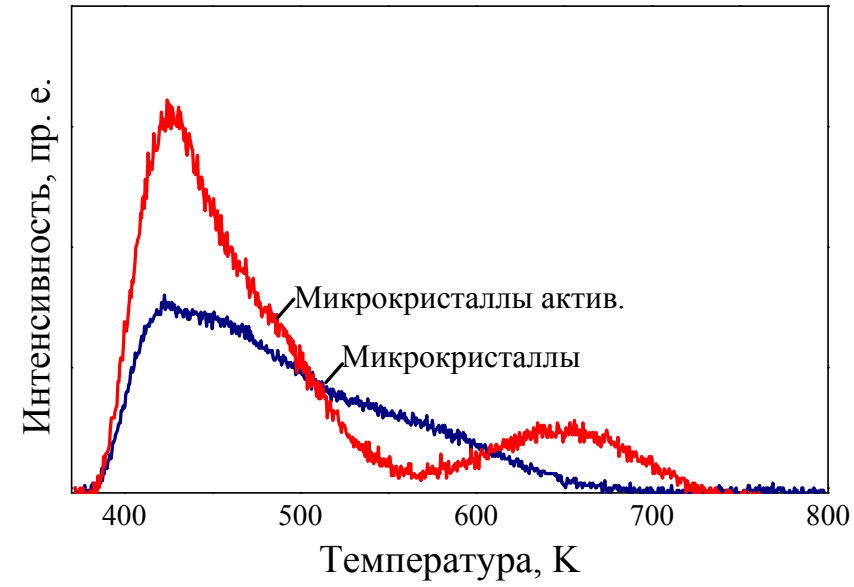

B

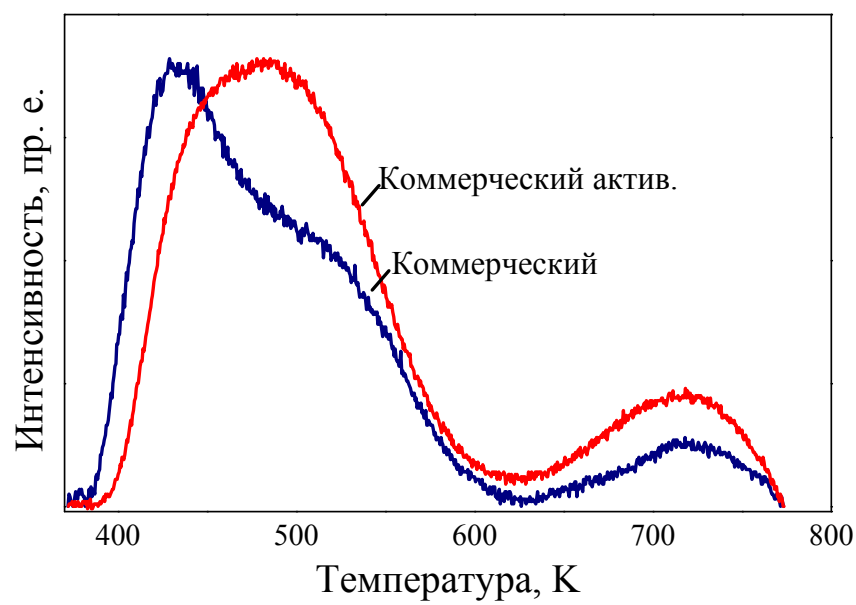

Рис. 3. Аммонийные ТПД-профили для исходных и активированных нанокристаллов (А), микрокристаллов (Б) и коммерческого (В) катализаторов 
В холостом опыте (без катализатора) конверсия пероксида водорода не наблюдалась. Кинетические кривые каталитического разложения пероксида водорода линеализируются в координатах первого порядка по $\mathrm{H}_{2} \mathrm{O}_{2}$ (рис. 5). Константа скорости первого порядка и ТОF при температуре $323 \mathrm{~K}$ в присутствии свежих катализаторов изменяются в ряду: микрокристаллы $<$ нанокристаллы < коммерческий катализатор (табл. 2, № 1, 3, 5). После активации щавелевой кислотой TOF разложения пероксида водорода увеличился для всех катализаторов. В случае

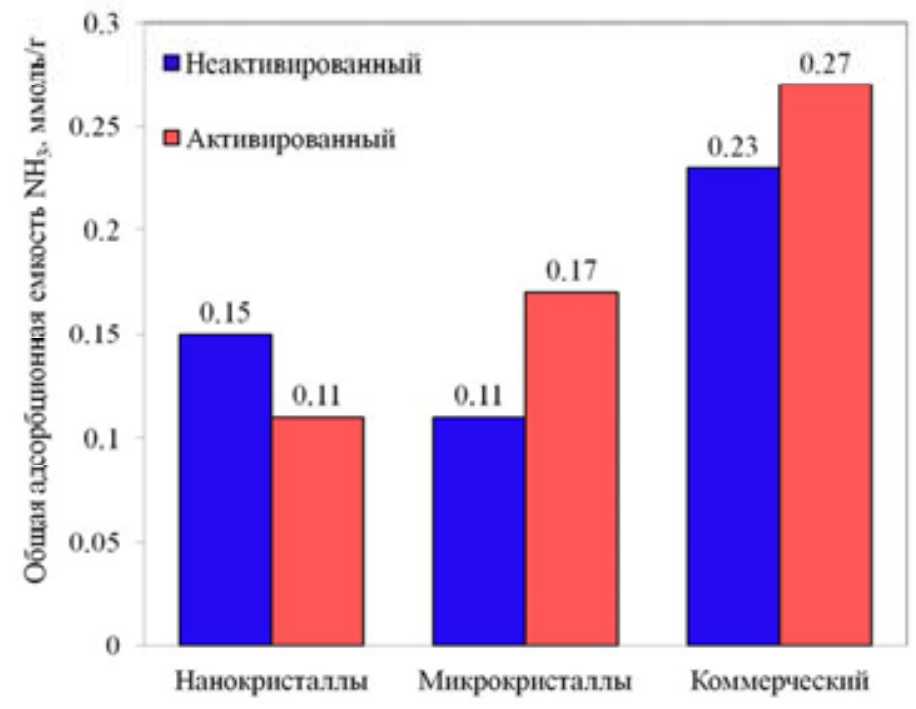

Рис. 4. Общая адсорбционная емкость $\mathrm{NH}_{3}$ для Fe-силикалитов и Fe-ZSM-5

A

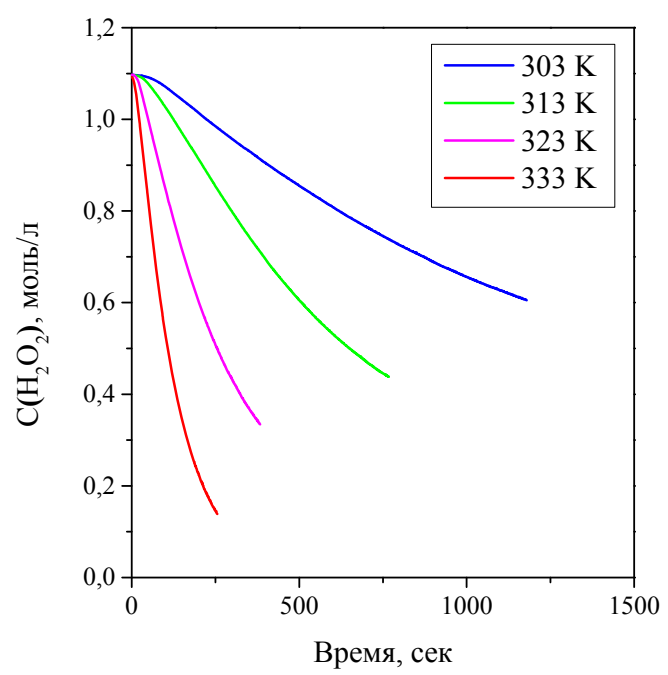

Б

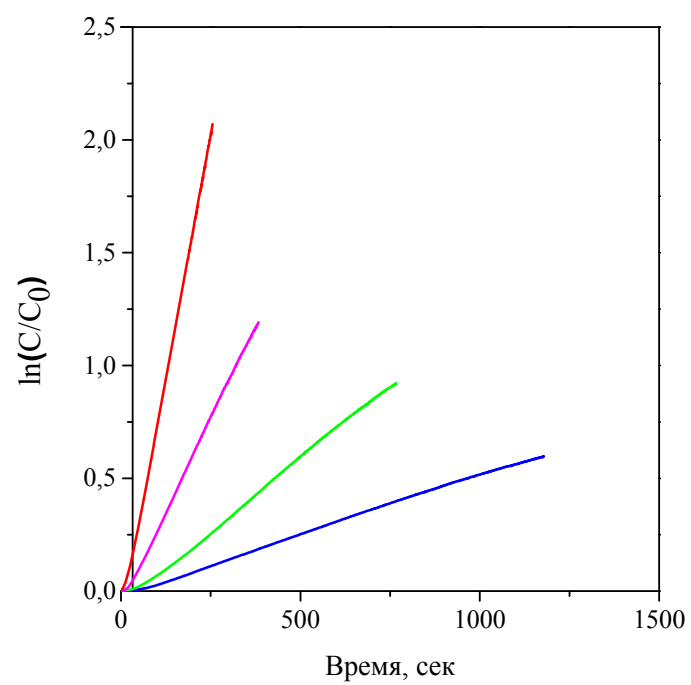

Рис. 5. Кинетики разложения $\mathrm{H}_{2} \mathrm{O}_{2}$ на микрокристаллах активированных (А) и их анаморфозы в координатах первого порядка (Б) 
Таблица 2. Кинетические данные разложения $\mathrm{H}_{2} \mathrm{O}_{2}\left(323 \mathrm{~K}, 1 \mathrm{M} \mathrm{H}_{2} \mathrm{O}_{2}, 20\right.$ г/л катализатора)

\begin{tabular}{|l|l|c|c|c|}
\hline Номер & \multicolumn{1}{|c|}{ Катализатор } & $\mathrm{k} \cdot 10^{3}, \mathrm{c}^{-1}$ & $\mathrm{TOF}, \mathrm{q}^{-1}$ & $\mathrm{E}_{\mathrm{a}}, \mathrm{\kappa}$ Дж/моль \\
\hline 1 & Нанокристаллы & 1.50 & 1240 & $70 \pm 2$ \\
\hline 2 & Нанокристаллы актив. & 1.45 & 1340 & $84 \pm 5$ \\
\hline 3 & Микрокристаллы & 0.17 & 130 & $53 \pm 1$ \\
\hline 5 & Микрокристаллы актив. & 2.44 & 1910 & $68 \pm 2$ \\
\hline 6 & Коммерческий & 1.54 & 2630 & $61 \pm 1$ \\
\hline
\end{tabular}

микрокристаллов образуются слабокислые каталитически активные $\alpha-\mathrm{Fe}_{2} \mathrm{O}_{3}$-подобные кластеры и дополнительные мезопоры (показано методами ЭСДО (рис. 2) и ТПД - $\mathrm{NH}_{3}$ (рис. 3)), что способствует диффузии реагентов и увеличению константы скорости. Исходные микрокристаллы чрезвычайно малоактивны в разложении пероксида водорода из-за низкой активности изолированных каркасных катионов железа, которые преобладают в данном образце. Константа скорости разложения $\mathrm{H}_{2} \mathrm{O}_{2}$ на коммерческом катализаторе увеличивается примерно 30 \% после его активации благодаря увеличению количества каталитически активных центров, таких как олигомерные оксидные кластеры Fe. Только для нанокристаллов активация не приводит к ускорению реакции и увеличению константы скорости, по-видимому, из-за вымывания 9 \% железа, но приводит к небольшому увеличению ТОF (табл. 2).

Кажущаяся энергия активации ( $\left.\mathrm{E}_{\mathrm{a}}\right)$ разложения $\mathrm{H}_{2} \mathrm{O}_{2}$ для всех катализаторов определялась в кинетических экспериментах при 303, 313, 323, 333 K (табл. 2). Для нанокристаллов $\mathrm{E}_{\mathrm{a}}$ равняется 70 кДж/моль, что является свидетельством преимущественно кинетического режима реакции, так как энергия активации разложения $\mathrm{H}_{2} \mathrm{O}_{2}$ в гомогенных растворах солей железа оценивается в (84 \pm 4$)$ кДж/моль [48]. Энергия активации около 53 кДж/моль для микрокристаллов указывает на существенный вклад внутренних диффузионных ограничений скорости реакции благодаря значительно меньшей энергии активации диффузии. Энергия активации значительно возрастает после активации нанокристаллов и микрокристаллов в результате снижения внутренних диффузионных ограничений. На микрокристаллах реакция идет в кинетическом режиме в связи с расширением мезопористой структуры микроразмерных кристаллов. Энергия активации коммерческого катализатора практически не меняется при активации образца из-за существенных диффузионных ограничений катализатора. Однако в данном случае диффузионные ограничения обусловлены малой площадью наружной поверхности кристаллитов (от 1/5 до 1/10 по сравнению с нанокристаллами и микрокристаллами соответственно). Кроме того, как было показано ранее $[49,50]$, пузырьки кислорода, образующиеся при разложении $\mathrm{H}_{2} \mathrm{O}_{2}$ на внешней поверхности кристаллитов, препятствуют доступу реагентов к каталитически активным центрам.

\section{Пероксидное окисление метана}

При проведении холостого эксперимента (в отсутствие катализатора) не наблюдалась конверсия ни метана, ни пероксида водорода. Это свидетельствует об отсутствии катализа метал-

$$
-406-
$$


Таблица 3. Пероксидное окисление метана на Fe-содержащих катализаторах $(323 \mathrm{~K}, 30$ бар, 30 мин, $1 \mathrm{M}$ $\mathrm{H}_{2} \mathrm{O}_{2}, 2.7$ г/л катализатора, $\mathrm{pH}_{\text {нач. }} 3.5$ )

\begin{tabular}{|c|c|c|c|c|c|c|c|c|c|c|}
\hline \multirow[b]{2}{*}{ Номер } & \multirow[b]{2}{*}{ Катализатор } & \multicolumn{2}{|c|}{$\mathrm{H}_{2} \mathrm{O}_{2}$} & \multicolumn{2}{|c|}{$\mathrm{CH}_{4}$} & \multirow{2}{*}{$\begin{array}{c}\text { TOF } \\
\left(\mathrm{H}_{2} \mathrm{O}_{2}\right) / \\
\text { TOF } \\
\left(\mathrm{CH}_{4}\right)\end{array}$} & \multicolumn{4}{|c|}{ Селективность, \% } \\
\hline & & $\begin{array}{c}\text { Конвер- } \\
\text { сия, \% }\end{array}$ & TOF, $\mathbf{4}^{-1}$ & $\begin{array}{l}\text { Конвер- } \\
\text { сия, \% }\end{array}$ & TOF, $\mathrm{\Psi}^{-1}$ & & $\mathrm{MeOH}$ & $\mathrm{HCOOH}$ & $\mathrm{CO}$ & $\mathrm{CO}_{2}$ \\
\hline 1 & Нанокристаллы & 12 & 360 & 0,14 & 20 & 16.2 & 14 & 41 & 1.6 & 44 \\
\hline 2 & $\begin{array}{l}\text { Нанокристаллы } \\
\text { актив. }\end{array}$ & 12 & 430 & 0.22 & 40 & 9.2 & 12 & 65 & 0.7 & 23 \\
\hline 3 & Микрокристаллы & 9 & 290 & 0.16 & 30 & 11.6 & 16 & 64 & 0.9 & 19 \\
\hline 4 & $\begin{array}{l}\text { Микрокристаллы } \\
\text { актив. }\end{array}$ & 13 & 440 & 0.30 & 50 & 9.5 & 12 & 72 & 0.6 & 13 \\
\hline 5 & Коммерческий & 15 & 950 & 0.42 & 140 & 6.6 & 36 & 26 & 0.6 & 37 \\
\hline 6 & $\begin{array}{l}\text { Коммерческий } \\
\text { актив. }\end{array}$ & 20 & 1400 & 1.02 & 340 & 4.2 & 10 & 84 & 0.9 & 5,1 \\
\hline
\end{tabular}

лическими стенками реактора процесса пероксидного окисления метана. Конверсия метана на Fe-содержащих катализаторах варьировалась от 0.14 до 1.02 \% (табл. 3, № 1-6). Обработка всех катализаторов щавелевой кислотой привела к значительному улучшению их активности (сравнивая значения конверсии и ТOF). Коммерческий актив. катализатор оказался наиболее активным как в окислении метана, так и в разложении пероксида водорода. Активация по-разному влияет на конверсию окислителя для разных катализаторов. Конверсия пероксида водорода увеличивается на 5 и 4 \% для коммерческого и микрокристаллического катализаторов соответственно. Активация нанокристаллов не приводит к увеличению конверсии $\mathrm{H}_{2} \mathrm{O}_{2}$, но приводит к незначительному увеличению ТОF. Подобный эффект наблюдался и при проведении реакции в отсутствие метана. Следует обратить внимание, что в присутствии субстрата существенно снижается конверсия окислителя и значения TOF его разложения (за исключением микрокристаллов из-за существенного диффузионного контроля). Поэтому разумно сделать вывод, что одни и те же каталитически активные центры участвуют, по крайней мере на ранней стадии, как в разложении пероксида водорода (в кислой среде, как правило, осуществляется свободнорадикальный механизм [51]), так и в окислении метана пероксидом водорода.

Отметим, что стехиометрические соотношения для перекиси водорода и метана являются следующими: для образования $\mathrm{CO}_{2}-4: 1$; для $\mathrm{HCOOH}-3: 1$; для $\mathrm{CO}-2: 1$; для $\mathrm{CH}_{3} \mathrm{OH}-1: 1$. Coотношение активности катализаторов в расходовании пероксида водорода и окислении метана $\left(\mathrm{TOF}\left(\mathrm{H}_{2} \mathrm{O}_{2}\right) / \mathrm{TOF}\left(\mathrm{CH}_{4}\right)\right)$ для прокаленных катализаторов варьировалось от 16.2 для нанокристаллов до 6.6 для коммерческого катализатора. Для активированных катализаторов наблюдалось существенне уменьшение соотношения $\mathrm{TOF}\left(\mathrm{H}_{2} \mathrm{O}_{2}\right) / \mathrm{TOF}\left(\mathrm{CH}_{4}\right)$. Однако даже для коммерческого актив. катализатора это соотношение (4.2) было примерно на треть выше, чем стехиометрическое соотношение для образования муравьиной кислоты. Следовательно, можно предположить вклад свободнорадикального механизма в разложение $\mathrm{H}_{2} \mathrm{O}_{2}$.

После завершения реакции количество железа, вымытого в реакционный раствор, варьировалось от 0.26 до 2.24 \%. В связи с этим проведены экспериментальные исследования каталитического вклада гомогенных ионов $\mathrm{Fe}^{3+}$, смытых в раствор. Реакцию проводили с ис-

$$
-407-
$$


пользованием отфильтрованного раствора после окисления метана на коммерческом актив. катализаторе и гомогенном катализаторе $(0,31$ мМ раствор нитрата железа) с концентрацией ионов железа, идентичных его количеству в коммерческом катализаторе. В первом случае катионы $\mathrm{Fe}$, смытые в раствор в ходе реакции, оказались неактивными ни к разложению пероксида водорода, ни к окислению метана и его кислородосодержащих соединений. Во втором эксперименте гомогенный катализатор был очень малоактивным в окислении метана при почти 100\%-й селективности по $\mathrm{CO}_{2}$. В то же время данный катализатор показал высокую активность в разложении пероксида водорода: наблюдаемый TOF (683 ч-1) был выше по сравнению со всеми исследованными силикалитами, но ниже, чем для коммерческого катализатора. Следовательно, вымываемые ионы $\mathrm{Fe}^{3+}$ могут катализировать только неселективное разложение пероксида водорода.

Основными продуктами окисления метана в наших экспериментах были метанол, муравьиная кислота и $\mathrm{CO}_{2}$. Количество $\mathrm{CO}$ было на порядки меньше по сравнению с остальными продуктами (селективность составляет около 1 \%). Количество метилгидропероксида было значительно меньше, чем трех основных продуктов (что было показано методом $\mathrm{H}^{1}$ ЯМР для микрокристаллов актив.), однако на данном этапе мы не смогли определить количество формальдегида. Именно поэтому мы оценили ТОF окисления метана по выходам метанола, муравьиной кислоты и $\mathrm{CO}_{2}$. TOF варьируется от 20 до 340 ч $^{-1}$ и возрастает в ряду как для исходных, так и для активированных образцов: нанокристаллы < микрокристаллы < коммерческий. Для всех катализаторов наблюдается увеличение TOF после активации, и для коммерческого катализатора TOF увеличилось более чем в два раза (с 140 до 340 ч $\left.^{-1}\right)$.

Селективность катализаторов по отношению к основным продуктам и её изменение в результате активации катализатора были изучены. Коммерческий катализатор оказался наиболее активным в конверсии метана и селективным в отношении первого оксигената (метанол 36 \%), в то время как нанокристаллы, наименее активные в окислении метана, наиболее селективны по отношению к продукту глубокого окисления $\left(\mathrm{CO}_{2}, 44\right.$ \%). Катализатор микрокристаллы оказался наиболее селективным по отношению к муравьиной кислоте (64 \%) В целом селективность по $\mathrm{HCOOH} \mathrm{и} \mathrm{CO}_{2}$ составляла около 80-85 \%, и чем выше селективность по $\mathrm{HCOOH}$, тем ниже селективность по $\mathrm{CO}_{2}$. Эти наблюдения могут указывать на существование различных путей окисления метана на исследуемых катализаторах. Кроме того, возможно, что муравьиная кислота не промежуточный продукт окисления метанола до $\mathrm{CO}_{2}$.

Активация щавелевой кислотой приводит к формированию внекаркасных $\mathrm{FeO}_{\mathrm{x}}$-центров (рис. 2) и увеличению общей кислотности катализаторов; уменьшение селективности по $\mathrm{CO}_{2}$ и метанолу при значительном увеличении селективности по муравьиной кислоте наблюдается для всех исследованных образцов. Селективность по муравьиной кислоте достигает 84 \% на коммерческом актив. катализаторе (табл. 3, № 6). Таким образом, формирование внекаркасных $\mathrm{FeO}_{\mathrm{x}}$-центров и увеличение общей кислотности являются ключевыми факторами в процессе пероксидного окисления метана.

Селективность по НСООН коррелирует с числом сильных бренстедовских кислотных центров и концентрацией/размером оксидных кластеров $\mathrm{Fe}$ (олигомерные комплексы или $\mathrm{Fe}_{2} \mathrm{O}_{3}$-подобные наночастицы), но обратно пропорциональна силе бренстедовских кислотных центров. Бренстедовские кислотные центры способствуют активации метана. Чем выше кон- 
центрация бренстедовских кислотных центров, тем более селективна трансформация $\mathrm{CH}_{4}$ в $\mathrm{HCOOH} \mathrm{[52].} \mathrm{Однако} \mathrm{данное} \mathrm{соотношение} \mathrm{изменяется,} \mathrm{когда} \mathrm{сила} \mathrm{бренстедовских} \mathrm{кислотных}$ центров увеличивается, что приводит к отличиям в селективности по $\mathrm{HCOOH}$, наблюдаемым для Fе-силикалитов и коммерческого H-ZSM-5.

Тот факт, что селективность значительно снижается по отношению к $\mathrm{CO}_{2}$, но увеличивается по НСООН при активации катализатора, можно объяснить двумя причинами. Во-первых, это сильное взаимодействие $\mathrm{HCOOH} \mathrm{с} \mathrm{ионами} \mathrm{Fe}^{3+}$. Комплексообразование между интермедиатом реакции и железом может предотвратить дальнейшее окисление $\mathrm{HCOOH}[53,54]$. Повидимому, стабильность $\mathrm{Fe}$ (III)-формиатных комплексов зависит от природы $\mathrm{Fe}^{3+}$ комплексов, биядерные и олигомерные оксокластеры являются более стабильными, чем изолированные ионы и $\mathrm{Fe}_{2} \mathrm{O}_{3}$-подобные наночастицы [54]. Во-вторых, это стабилизация высоковалентных оксокомплексов железа (феррильные частицы $\mathrm{Fe}^{\mathrm{IV}}=\mathrm{O}$ ), образованных взаимодействием ионов $\mathrm{Fe}^{2+}$ на поверхности с молекулами пероксида водорода в Fе-оксидных кластерах. Феррильные частицы, как известно [55], менее активный, но гораздо более селективный окислитель, чем $\mathrm{OH}$ радикал. Формирование феррильных частиц в водном растворе $\mathrm{H}_{2} \mathrm{O}_{2}$ более вероятно для активированных катализаторов, содержащих большее количество Fe-оксидных кластеров [35]. Таким образом, эффект повышения селективности по НСООН наиболее ярко выражен для коммерческого активированного образца, где кислые Fе-содержащие оксидные центры сильнее и более многочисленны, чем в Fе-силикалитах.

Метанол можно рассматривать как продукт прямого окисления метана, который, как полагают, образуется через взаимодействие метильного и гидроксильного свободных радикалов в присутствии цеолитных катализаторов [56]. Так как радикальный механизм характерен для образования метанола, можно предположить, что селективность по отношению к $\mathrm{CH}_{3} \mathrm{OH}$ зависит от трех факторов, которыми являются площадь внешней поверхности (определяет скорость гашения радикалов), концентрация сильных кислотных центров и ионов $\mathrm{Fe}^{3+}$ (активные к образованию метильных и гидроксильных радикалов соответственно [53]). Влияние внешней поверхности (и, следовательно, размера кристаллитов) наиболее ярко выражено. Селективность по $\mathrm{CH}_{3} \mathrm{OH}$ для нанокристаллов самая низкая (табл. 3, № 1) при наибольшей площади внешней поверхности, а самая высокая наблюдается для неактивированного коммерческого образца с минимальной площадью поверхности, который состоит из крупных сросшихся агрегатов (табл. 3, № 5).

\section{Заключение}

Fe-MFI-катализаторы с различными текстурными и морфологическими свойствами были приготовлены различными методами и изучены в реакции пероксидного окисления метана в водной среде. Полученные результаты показали, что каталитическая активность и селективность по основным продуктам реакции (метанол, муравьиная кислота и диоксид углерода) зависят от трех ключевых факторов: площади внешней поверхности/размера кристаллитов, концентрации бренстедовских кислотных центров и концентрации/размера оксидных кластеров Fe.

Активация всех катализаторов щавелевой кислотой приводит к уменьшению селективности окисления метана по отношению к $\mathrm{CO}_{2}$ и метанолу. В то же время возрастает селективность

$$
-409-
$$


по муравьиной кислоте, вероятно из-за увеличения количества олигомерных кластеров оксида железа (по данным ЭСДО). Кроме того, наблюдается увеличение числа кислотных центров (по данным ТПД- $\mathrm{NH}_{3}$ ), которые могут образовывать стабильные формиатные комплексы.

Корреляция селективности с вышеописанными факторами позволила сформулировать предположение о существовании различных путей, ведущих к образованию метанола/ $\mathrm{CO}_{2}$ и муравьиной кислоты из метана на катализаторах Fe-MFI.

Вызывает оптимизм тот факт, что доля пероксида водорода на коммерческом активированном катализаторе, расходуемая на окисление метана, весьма высока (до 75 \%) по сравнению с разложением самой $\mathrm{H}_{2} \mathrm{O}_{2}$. В связи с этим представляется вполне реальным синтезировать железосодержащие катализаторы для селективного окисления легких алканов в мягких условиях с $\mathrm{H}_{2} \mathrm{O}_{2}$ в качестве окислителя.

\section{Благодарности}

Работа выполнена при финансовой поддержке Российского научного фонда (грант 14-1301155).

\section{Список литературы}

1. Thauer R.K. Functionalization of methane in anaerobic microorganisms. Angew. Chem., Int. Ed. 2010. Vol. 49, P. 6712-6713.

2. Blanksby S.J., Ellison G.B. Bond Dissociation Energies of Organic Molecules. Acc. Chem. Res. 2003. Vol. 36, P. 255.

3. Shilov A.E., Shteiman A.A., Methane hydroxylation: a biomimetic approach. Rus. Chem. Rev. 2012. Vol. 81, P. 291-316.

4. Olah G.A., Goeppert A., Surya Prakash G.K. Beyond Oil and Gas: the Methanol Economy: Second Edition. Wiley-VCH, Weinheim, 2009, 334 p.

5. Rostrup-Nielsen J. Production of synthesis gas. Catal. Today. 1993. Vol. 18, P. 305-324.

6. Holmen A. Direct conversion of methane to fuels and chemicals. Catal. Today. 2009. Vol. 142, P. 2-8.

7. Hashiguchi B.G., Hoevelmann C.H., Bischof S.M., Lokare K.S., Leung C.H., Periana R.A., Crabtree R.H. In Energy Production and Storage: Inorganic Chemical Strategies for a Warming World. Wiley, New York. 2010. 426 p.

8. Benlounes O., Mansouri S., Rabia C., Hocine S. Direct oxidation of methane to oxygenates over heteropolyanions. J. Nat. Gas Chem. 2008. Vol. 17, P. 309-312.

9. Kucherov A.V., Nissenbaum V.D., Kucherova T.N., Kustov L.M. Catalytic oxidation of methane by nitrous oxide on H[Al]ZSM-5 zeolite, silicalite, and amorphous $\mathrm{SiO}_{2}$ modified by iron, silver, and gadolinium ions. Kinet. Catal. 2002. Vol. 43, P. 711-723.

10. Knops-Gerritsa P.P., Smith W.J. Methane partial oxidation in new iron zeolite topologies. Stud. Surf. Sci. Catal. 2000. Vol. 130, P. 3531-3536.

11. Otsuka K., Wang Y. Direct conversion of methane into oxygenates. Appl. Catal. A. 2001. Vol. 222, P. 145-161.

12. Arutyonov V. Direct Methane to Methanol: Foundations and Prospects of the Process, Elsevier B.V., Amsterdam, 2014. 309 p. 
13. Zhang Z., Guo Z., Ji S. Numerical simulation of packed-bed reactor for oxidative coupling of methane. J. Energ. Chem. 2015. Vol. 24, P. 23-30.

14. Alvarez-Galvan M.C., Mota N., Ojeda M., Rojas S., Navarro R.M., Fierro J.L.G. Direct methane conversion routes to chemicals and fuels. Catal. Today. 2011. Vol. 171, P. 15-23.

15. Starokon E.V., Parfenov M.V., Arzumanov S.S., Pirutko L.V., Stepanov A.G., Panov G.I. Oxidation of methane to methanol on the surface of FeZSM-5 zeolite. J. Catal. 2013. Vol. 300, P. $47-54$.

16. Olivos-Suarez A.I., Szecsenyi A., Hensen E.J.M., Ruiz-Martinez J., Pidko E.A., Gascon J. Strategies for the direct catalytic valorization of methane using heterogeneous catalysis: challenges and opportunities. ACS Catal. 2016. Vol. 6, P. 2965-2981.

17. Romakh V.B., Therrien B., Suss-Fink G., Shul'pin G.B. Synthesis, molecular structure, and catalytic potential of the tetrairon complex $\left[\mathrm{Fe}_{4}\left(\mathrm{~N}_{3} \mathrm{O}_{2}-\mathrm{L}\right)_{4}(\mu-\mathrm{O}) 2\right]^{4+}(\mathrm{L}=1$-carboxymethyl-4,7dimethyl-1,4,7- triazacyclononane). Inorg. Chem. 2007. Vol. 46, P. 3166-3175.

18. Sorokin A.B., Kudrik E.V., Alvarez L.X., Afanasiev P. Millet J.-M.M., Bouchu D. Oxidation of methane and ethylene in water at ambient conditions. Catal. Today. 2010. Vol. 157, P. 149-154.

19. Ab Rahim M.H., Forde M.M., Hammond C., Jenkins R.L., Dimitratos N., Lopez-Sanchez J.A., Carley A.F., Taylor S.H., Willock D.J., Hutchings G.J. Systematic study of the oxidation of methane using supported gold palladium nanoparticles under mild aqueous conditions. Top. Catal. 2013. Vol. 56, P. $1843-1857$.

20. Yuan Q., Deng W., Zhang Q., Wang Y. Osmium-catalyzed selective oxidations of methane and ethane with hydrogen peroxide in aqueous medium. Adv. Synth. Catal. 2007. Vol. 349, P. 11991209.

21. Centi G., Perathoner S., Torre T., Verduna M.G. Catalytic wet oxidation with $\mathrm{H}_{2} \mathrm{O}_{2}$ of carboxylic acids on homogeneous and heterogeneous Fenton-type catalysts. Catal. Today. 2000. Vol. 55, P. 6169.

22. Pestunova O.P., Elizarova G.L., Ismagilov Z.R., Kerzhentsev M.A., Parmon V.N. Detoxication of water containing 1,1-dimethylhydrazine by catalytic oxidation with dioxygen and hydrogen peroxide over $\mathrm{Cu}$ - and Fe-containing catalysts Cat. Tod. 2002. Vol. 75, P. 219-225.

23. Makhotkina O., Kuznetsova E. Preis S.V. Catalytic detoxification of 1,1-dimethylhydrazine aqueous solutions in heterogeneous Fenton system. Appl. Catal. B: Env. 2006. Vol. 68, P. 85-91.

24. Kondru A., Kumar P., Chand S. Catalytic wet peroxide oxidation of azo dye (Congo red) using modified Y zeolite as catalyst. J. Hazard. Mat. 2009. Vol. 166, P. 342-347.

25. Taran O.P., Yashnik S.A., Ayusheev A.B., Piskun A.S., Prihod'ko R.V., Ismagilov Z.R., Goncharuk V.V., Parmon V.N. Cu-containing MFI zeolites as catalysts for wet peroxide oxidation of formic acid as model organic contaminant. Appl. Catal. B: Env. 2013. Vol. 140-141, P. 506-515.

26. Prihod'ko R.V., Stolyarova I.V., Gunduz G., Taran O.P., Yashnik S.A., Parmon V.N., Goncharuk V.V. Fe-exchanged zeolites as materials for catalytic wet peroxide oxidation. Degradation of Rodamine G dye. Appl. Catal. B: Env. 2011. Vol. 104, P. 201-210.

27. Taran O.P., Zagoruiko A.N., Ayusheev A.B., Yashnik S.A., Prihod'ko R.V., Ismagilov Z.R., Goncharuk V.V., Parmon V.N. $\mathrm{Cu}$ and Fe-containing ZSM-5 zeolites as catalysts for wet peroxide oxidation of organic contaminants: Reaction kinetics. Res. on Chem. Inter. 2015. Vol. 41. P. 95219537. 
28. Snyder B.E.R., Vanelderen P., Bols M.L., Hallaert S.D., Böttger L.H., Ungur L., Pierloot K., Schoonheydt R.A., Sels B.F., Solomon E.I. The active site of low-temperature methane hydroxylation in iron-containing zeolites. Nature. 2016. Vol. 536, P. 317-321.

29. Grundner S., Luo W., Sanchez-Sanchez M., Lercher J.A. Synthesis of single-site copper catalysts for methane partial oxidation. Chem. Commun. 2016. Vol. 52, P. 2553-2556.

30. Kuzmin A.O., Elizarova G.L., Matvienko L.G., Savinova E.R., Parmon V.N. Partial oxidation of light paraffins with hydrogen peroxide in the presence of peroxocomplexes of copper(II) hydroxide Mend. Commun. 1998. Vol. 8, P. 210-212.

31. Lysova A.A., Kuzmin A.O., Elizarova G.L., Parmon V.N. Stationary kinetics of light olefin oxidation by hydrogen peroxide in aqueous alkali solutions in the presence of $\mathrm{Fe}(\mathrm{III})$ oxide. Kinet. Catal. 2002. Vol. 43, P. 778-784.

32. Hammond C., Forde M.M., Ab Rahim M.H., Thetford A., He Q., Jenkins R.L., Dimitratos N., Lopez-Sanchez J.A., Dummer N.F., Murphy D.M., Carley A.F., Taylor S.H., Willock D.J., Stangland E.E., Kang J., Hagen H., Kiely C.J., Hutchings G.J. Direct catalytic conversion of methane to methanol in an aqueous medium by using copper-promoted Fe-ZSM-5. Angew. Chem. Int. Ed. 2012. Vol. 51, P. 5129-5133.

33. Hammond C., Dimitratos N., Jenkins R.L., Lopez-Sanchez J.A., Kondrat S.A., Ab Rahim M.H., Forde M.M., Thetford A., Taylor S.H., Hagen H., Stangland E.E., Kang J.H., Moulijn J.M., Willock D.J., Hutchings G.J. Elucidation and evolution of the active component within $\mathrm{Cu} / \mathrm{Fe} /$ ZSM-5 for catalytic methane oxidation: from synthesis to catalysis. ACS Catal. 2013. Vol. 3, P. 689-699.

34. Hammond C., Dimitratos N., Lopez-Sanchez J.A., Jenkins R.L., Whiting G., Kondrat S.A., Ab Rahim M.H., Forde M.M., Thetford A., Hagen H., Stangland E.E., Moulijn J.M., Taylor S.H., Willock D.J., Hutchings G.J. Aqueous-phase methane oxidation over Fe-MFI zeolites; promotion through isomorphous framework substitution ACS Catal. 2013. Vol. 3, P. 1835-1844.

35. Shubin A.A., Ruzankin S.Ph., Zilberberg I.L., Parmon V.N. Distinct activity of the oxyl $\mathrm{Fe}^{\mathrm{III}}-\mathrm{O} \cdot$ group in the methane dissociation by activated iron hydroxide: DFT predictions. Chem. Phys. Lett. 2015. Vol. 640, P. 94-100.

36. Parkhomchuk E.V., Vanina M.P., Preis S. The activation of heterogeneous Fenton-type catalyst Fe-MFI. Catal. Commun. 2008. Vol. 9(3), P. 381-385.

37. Yashnik S.A., Ismagilov Z.R., Anufrienko V.F. Catalytic properties and electronic structure of copper ions in Cu-ZSM-5. Catal. Today. 2005. Vol. 110, P. 310-322.

38. Gregg S.J., Sing K.S.W. Adsorption, surface area, and porosity, Academic Press, London, $1982,304 \mathrm{p}$.

39. Jaroniec M., Kruk M., Olivier J.P. Standard nitrogen adsorption data for characterization of nanoporous silicas. Langmuir. 1999. Vol. 15, P. 5410-5413.

40. Kruk M., Jaroniec M., Ko C.H., Ryoo R. Characterization of the porous structure of SBA-15. Chem. Mater. 2000. Vol. 12, P. 1961-1968.

41. Sashkina K.A., Parkhomchuk E.V., Rudina N.A., Parmon V.N. The role of zeolite Fe-ZSM-5 porous structure for heterogeneous Fenton catalyst activity and stability. Micropor. Mesopor. Mater. 2014. Vol. 189, P. 181-188.

42. Lever A.B.P. Inorganic Electron Spectroscopy, Elsevier, Amsterdam, 1984, 863 p. 
43. Malykhin S.E., Anufrienko V.F., Hensen E.J.M., Parkhomchuk E.V., Larina T.V., Jidomirov G.M. Distortion of the tetrahedral coordination of Fe(III) ions stabilized in ZSM-5 zeolite framework. J. Struct. Chem. 2007. Vol. 48, P. 914-920.

44. Janchen J., Vorbeck G., Stach H., Parlitz B., van Hooff J.H.C. Adsorption calorimetric and spectroscopic studies on isomorphous substituted (Al, Fe, In, Ti) MFI zeolites. Stud. Surf. Sci. Catal. 1995. Vol. 94, P. 108-115.

45. Lonyi F., Valyon J. On the interpretation of the $\mathrm{NH}_{3}$-TPD patterns of H-ZSM-5 and H-mordenite. Micropor. Mesopor. Mater. 2001. Vol. 47, P. 293-301.

46. Gorte R.J. What do we know about the acidity of solid acids? Catal. Lett. 1991. Vol. 62, P. $1-13$.

47. Katada N., Igi H., Kim J.-H., Niwa M. Determination of the acidic properties of zeolite by theoretical analysis of temperature-programmed desorption of ammonia based on adsorption equilibrium. J. Phys. Chem. B 1997. Vol. 101, P. 5969-5977.

48. Sashkina K.A., Polukhin A.V., Labko V.S., Ayupov A.B., Lysikov A.I., Parkhomchuk E.V. Fesilicalites as heterogeneous Fenton-type catalysts for radiocobaltremoval from EDTA chelates. Appl. Catal. B: Env. 2016. Vol. 85, 353-361.

49. Koptyug I.V., Kulikov A.V., Lysova A.A., Kirillov V.A., Parmon V.N., Sagdeev R.Z. Chem. Sustain. Develop. 2003. Vol. 11, P. 109-116.

50. Bluemich B., Datsevich L.B., Jess A., Oehmichen Th., Ren X., Stapf S. Chaos in catalyst pores. Can we use it for process development? Chem. Eng. J. 2007. Vol. 134, P. 35-44.

51. Sychev A.Ya., Isak V.G. Iron compounds and the mechanisms of the homogeneous catalysis of the activation of $\mathrm{O}_{2}$ and $\mathrm{H}_{2} \mathrm{O}_{2}$ and of the oxidation of organic substrates. Rus. Chem. Rev. 1995. Vol. 64, P. $1105-1130$.

52. Rahman A.K.Md.L., Kumashiro M., Ishihara T. Direct synthesis of formic acid by partial oxidation of methane on H-ZSM-5 solid acid catalyst Catal. Commun. 2011. Vol. 12, P. 1198-1200.

53. Foustoukos D.I., Stern J.C. Oxidation pathways for formic acid under low temperature hydrothermal conditions: Implications for the chemical and isotopic evolution of organics on Mars Geochim. Cosmochim. Acta. 2012. Vol. 76, P. 14-28.

54. Long Y., Charbouillot T., Brigante M., Mailhot G., Delort A.-M., Chaumerliac N., Deguillaume L. Evaluation of modeled cloud chemistry mechanism against laboratory irradiation experiments: The $\mathrm{H}_{\mathrm{x}} \mathrm{O}_{\mathrm{y}}$ /iron/carboxylic acid chemical system. Atmos. Environ. 2013. Vol. 77, P. 686-695.

55. Gonzalez-Olmos R., Holzer F., Kopinke F.-D., Georgi A. Indications of the reactive species in a heterogeneous Fenton-like reaction using Fe-containing zeolites. Appl. Catal. A: Gen. 2011. Vol. 398, P. 44-53.

56. Han S., Martenak D.J., Palermo R.E., Pearson J.A., Walsh D.E. Partial oxidation of methane to liquid hydrocarbons over ZSM-5 catalyst. J. Catal. 1992. Vol. 136, P. 578-583. 